\title{
PENGETAHUAN, SIKAP, DAN PERILAKU TENAGA PENOLONG PERSALINAN DI PUSKESMAS KOTA MANADO TERHADAP PROFILAKSIS VITAMIN K
}

\author{
${ }^{1}$ Sandy Suoth \\ ${ }^{2}$ Stevanus Gunawan \\ ${ }^{2}$ Vivekenanda Pateda
}

\author{
${ }^{1}$ Kandidat Skripsi Fakultas Kedokteran Universitas Sam Ratulangi Manado \\ ${ }^{2}$ Bagian Ilmu Kesehatan Anak Fakultas Kedokteran Universitas Sam Ratulangi Manado \\ Email: SandySuoth@ymail.com
}

\begin{abstract}
In Indonesia, the infant mortality rate (IMR) is 41.4 per 1.000 live births. It is projected that the rate will be 18 per 1.000 live births in 2025. One of the efforts to decrease the IMR is prevention of the occurrence of cerebral hemorrhage in newborns. This hemorrhage is caused by coagulation disorders due to a deficiency of vitamin K. Vitamin $\mathrm{K}$ injection is essential for newborns to prevent this hemorrhage. This was a descriptive study with a cross-sectional design that was conducted by using questionnaires. Respondents were taken from 15 community health centers in Manado. The results showed that of the 102 birth aattendants: $60.8 \%$ had good knowledge; $69.6 \%$ thought that vitamin $\mathrm{K}$ prophylaxis should be administered to all newborn babies; $57.8 \%$ agreed that this prophylaxis should be administered after birth; $64.7 \%$ thought that vitamin $\mathrm{K}$ prophylaxis could prevent cerebral hemorrhage of the newborns; $78.4 \%$ agreed that vitamin $\mathrm{K}$ was available at the community health centers; $56.9 \%$ knew that vitamin $\mathrm{K}$ prophylaxis did not cause any harmful side effects; $87.3 \%$ gave vitamin K prophylaxis to the newborns; $85.3 \%$ administered vitamin $\mathrm{K}$ to the newbornss immediately after birth; and $89.2 \%$ provided community health centers with vitamin K. Conclusion: In this study, most of the birth attendants had good knowledge, administered vitamin $\mathrm{K}$ prophylaxis to the newborns, and provided the health community centers with vitamin $\mathrm{K}$.
\end{abstract}

Keywords: cerebral hemorrhage, vitamin K prophylaxis, birth attendants

\begin{abstract}
Abstrak: Indonesia sebagai negara sedang berkembang mempunyai angka kematian bayi (AKB) 41,4 per 1.000 kelahiran hidup yang diproyeksikan menjadi 18 per 1.000 kelahiran hidup pada tahun 2025. Salah satu upaya menurukan AKB ialah dengan mencegah terjadinya perdarahan otak pada bayi baru lahir. Perdarahan ini diakibatkan gangguan proses koagulasi oleh kekurangan vitamin K. Pemberian injeksi vitamin K sangat penting pada bayi baru lahir untuk mencegah perdarahan otak tersebut. Penelitian bersifat deskriptif dengan desain potong lintang dan menggunakan kuesioner yang dibagikan pada tenaga penolong persalinan di 15 puskesmas Kota Manado. Hasil penelitian memperlihatkan bahwa dari 102 tenaga penolong : 60,8\% mempunyai tingkat pengetahuan tergolong baik; $69,6 \%$ berpendapat bahwa profilaksis vitamin $\mathrm{K}$ harus diberikan pada semua bayi baru lahir; 57,8\% setuju profilaksis vitamin $\mathrm{K}$ bermanfaat untuk mencegah perdarahan bayi baru lahir; 78,4\% setuju ketersediaan vitamin K di Puskesmas/Pondok bersalin; 56,9\% berpendapat bahwa tidak ada efek samping berbahaya untuk profilaksis vitamin K; 87,3\% tenaga kesehatan memberikan profilaksis vitamin K; 85,3\% tenaga kesehatan memberikan vitamin $\mathrm{K}$ segera setelah lahir; dan 89,2\% tenaga kesehatan menyediakan vitamin $\mathrm{K}$ di puskesmas/pondok bersalin. Simpulan: Sebagian besar tenaga penolong persalinan pada 15 puskesmas di kota Manado mempunyai tingkat pengetahuan tergolong baik, memberikan profilaksis vitamin $\mathrm{K}$, dan menyediakan vitamin $\mathrm{K}$ di puskesmas atau pondok bersalin.
\end{abstract}

Kata kunci: perdarahan serebral, profilaksis vitamin K, tenaga penolong persalinan 
Strategi pembangunan kesehatan menuju "Indonesia sehat 2011" mengisyaratkan bahwa seluruh pembangunan kesehatan ditujukan kepada upaya menyehatkan bangsa. ${ }^{1}$

Selama kurun waktu tiga dasawarsa terakhir, terlihat adanya penurunan angka mortalitas dan morbiditas neonatal secara bermakna di seluruh dunia, namun penurunan tersebut lebih terlihat nyata di negara-negara maju dibanding yang sedang berkembang. ${ }^{1,2}$

Perdarahan akibat defisiensi vitamin $\mathrm{K}$ (PDVK) merupakan penyakit yang disebabkan oleh kurangnya vitamin $\mathrm{K}$ dalam tubuh. PDVK adalah terjadinya perdarahan spontan atau perdarahan karena proses lain seperti pengambilan darah vena atau operasi yang disebabkan karena berkurangnya aktivitas faktor koagulasi yang tergantung vitamin K (Faktor II, VII, IX dan $\mathrm{X}$ ) sedangkan aktivitas faktor koagulasi yang tidak bergantung vitamin $\mathrm{K}$. kadar fibrinogen dan jumlah trombosit masih dalam batas normal. Kelainan tersebut akan segera membaik dengan pemberian vitamin $\mathrm{K}$ dan setelah penyebab koagulopati lain disingkirkan. ${ }^{3}$

PDVK termasuk penyakit yang cukup fatal. Angka kematian 10-15 \% yang umumnya terjadi pada bayi dalam rentang umur 2 minggu - 6 bulan, dengan akibat angka kecacatan 30-50 \%. Angka kejadian PDVK berkisar antara 1:200 sampai 1:400 kelahiran bayi yang tidak mendapat vitamin K profilaksis. ${ }^{3-5}$

Pencegahan yang harus dilakukan ialah profilaksis vitamin $\mathrm{K}$. Jenis vitamin $\mathrm{K}$ yang digunakan yaitu jenis vitamin K1 (phytomenadion) dengan dosis pemberian 1 $\mathrm{mg} / \mathrm{ml}$ dosis tunggal, suntik intramuskular, atau oral 3 kali $2 \mathrm{mg}$, diberikan pada waktu bayi baru lahir, umur 3 sampai 7 hari, dan pada saat bayi berumur 1-2 bulan. ${ }^{6-8}$

\section{METODE PENELITIAN}

Penelitian ini menggunakan kuesioner yang sebelumnya telah dilakukan uji validitas menggunakan metode Cronbach's Alpha. Berdasarkan harga kritik r Product Moment, nilai koefisien korelasi dengan jumlah $\mathrm{n}=30$ dan interval kepercayaan 95\% diperoleh nilai $r=0,361$. Dengan demikian nilai hasil uji validitas item pertanyaan pengetahuan, sikap dan perilaku $r>361$, sehingga dapat dikatakan semua item soal valid. Dengan menggunakan metode Cronbach's Alpha 95\% yaitu 0,635 > 0,361, dapat dikatakan bahwa semua item soal reliabel.

\section{HASIL PENELITIAN}

Tenaga penolong persalinan yang berada di 15 puskesmas di Kota Manado terdiri dari dokter dan bidan. Jumlah tenaga medis menurut pembagian kelompok pendidikan dapat dilihat pada Tabel 1 .

Tabel 1. Distribusi tenaga penolong persalinan menurut kelompok pendidikan

\begin{tabular}{lcc}
\hline \multirow{2}{*}{ Kelompok } & \multicolumn{2}{c}{ Jumlah } \\
\cline { 2 - 3 } & $\mathbf{n}$ & $\mathbf{\%}$ \\
\hline Bidan & 91 & 89,2 \\
Dokter & 11 & 10,8 \\
\hline Total & $\mathbf{1 0 2}$ & $\mathbf{1 0 0 , 0}$ \\
\hline
\end{tabular}

Tabel 2. Distribusi tenaga penolong persalinan menurut jenis kelamin

\begin{tabular}{lcc}
\hline \multirow{2}{*}{ Jenis kelamin } & \multicolumn{2}{c}{ Jumlah } \\
\cline { 2 - 3 } & $\mathbf{n}$ & $\mathbf{\%}$ \\
\hline Laki-laki & 5 & 4,9 \\
Perempuan & 97 & 95,1 \\
\hline Total & $\mathbf{1 0 2}$ & $\mathbf{1 0 0 , 0}$ \\
\hline
\end{tabular}

Tabel 3. Distribusi tenaga penolong persalinan berdasarkan usia

\begin{tabular}{lcc}
\hline \multirow{2}{*}{ Usia } & \multicolumn{2}{c}{ Jumlah } \\
\cline { 2 - 3 } & n & $\mathbf{\%}$ \\
\hline$<25$ tahun & 14 & 13,7 \\
25-30 tahun & 38 & 37,3 \\
31-35 tahun & 27 & 26,5 \\
36-40 tahun & 10 & 9,8 \\
$>$ 40 tahun & 13 & 12,7 \\
\hline Total & $\mathbf{1 0 2}$ & $\mathbf{1 0 0 , 0}$ \\
\hline
\end{tabular}


Tabel 4. Distribusi tenaga penolong persalinan berdasarkan lama kerja

\begin{tabular}{lcc}
\hline \multirow{2}{*}{ Lama kerja } & \multicolumn{2}{c}{ Jumlah } \\
\cline { 2 - 3 } & $\mathbf{n}$ & $\mathbf{\%}$ \\
\hline$<1$ tahun & 14 & 13,7 \\
1-2 tahun & 35 & 34,3 \\
3-4 tahun & 31 & 30,3 \\
$>$ 5 tahun & 22 & 21,7 \\
\hline Total & $\mathbf{1 0 2}$ & $\mathbf{1 0 0 , 0}$ \\
\hline
\end{tabular}

Tabel 5. Distribusi tenaga penolong persalinan menurut pengetahuan

\begin{tabular}{lcc}
\hline \multirow{2}{*}{ Pengetahuan } & \multicolumn{2}{c}{ Jumlah } \\
\cline { 2 - 3 } & n & \% \\
\hline Baik & 62 & 60,8 \\
Kurang & 39 & 38,2 \\
Buruk & 1 & 2,0 \\
\hline Total & $\mathbf{1 0 2}$ & $\mathbf{1 0 0 , 0}$ \\
\hline
\end{tabular}

Tabel 6. Distribusi tenaga penolong persalinan menurut nilai sikap

\begin{tabular}{|c|c|c|c|}
\hline \multirow{2}{*}{ Sikap } & \multicolumn{3}{|c|}{ Jumlah } \\
\hline & Setuju (\%) & Ragu (\%) & Tidak setuju (\%) \\
\hline $\begin{array}{l}\text { 1. Profilaksis vitamin } \mathrm{K} \text { harus diberikan } \\
\text { pada setiap bayi baru lahir }\end{array}$ & $71(69,6)$ & $31(30,4)$ & $0(0)$ \\
\hline $\begin{array}{l}\text { 2. Profilaksis vitamin K diberikan segera } \\
\text { setelah bayi lahir }\end{array}$ & $59(57,8)$ & $43(42,2)$ & $0(0)$ \\
\hline 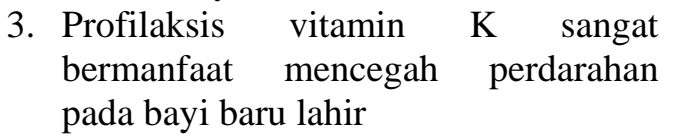 & $66(64,7)$ & $36(35,3)$ & $0(0)$ \\
\hline $\begin{array}{l}\text { 4. Vitamin k injeksi harus selalu tersedia } \\
\text { di Puskesmas/pondok bersalin }\end{array}$ & $80(78,4)$ & $22(21,6)$ & $0(0)$ \\
\hline 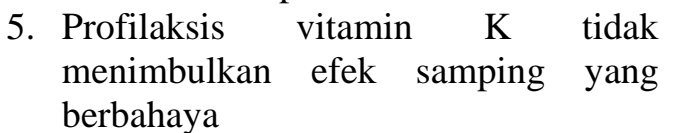 & $58(56,9)$ & $44(43,1)$ & $0(0)$ \\
\hline
\end{tabular}

Tabel 7. Distribusi tenaga penolong persalinan berdasarkan perilaku

\begin{tabular}{lcc}
\hline \multirow{2}{*}{ Perilaku } & \multicolumn{2}{c}{ Jumlah } \\
\cline { 2 - 3 } & Ya (\%) & Tidak (\%) \\
\hline 1. Apakah Anda selalu memberikan profilaksis & $89(87,3)$ & $13(12,7)$ \\
$\begin{array}{l}\text { vitamin K pada semua bayi baru lahir? } \\
\text { 2. Apakah Anda memberikan vitamin K segera }\end{array}$ & $87(83,3)$ & $15(14,7)$ \\
$\begin{array}{l}\text { setelah lahir? } \\
\text { 3. Apakah Anda selalu menyediakan vitamin K } \\
\text { pada pondok bersalin/puskesmas? }\end{array}$ & $91(89,2)$ & $11(10,7)$ \\
\hline
\end{tabular}

\section{BAHASAN}

Tingkat pengetahuan tenaga penolong persalinan pada 15 puskesmas di Kota Manado sebagian besar tergolong baik. Sebagian besar tenaga penolong persalinan berpendapat bahwa profilaksis vitamin $\mathrm{K}$ bayi baru lahir harus diberikan pada semua bayi baru lahir. Selain itu sebagian besar berpendapat bahwa profilaksis vitamin $\mathrm{K}$ bermanfaat untuk mencegah perdarahan bayi baru lahir, dan setuju vitamin $\mathrm{K}$ harus selalu tersedia di puskesmas/pondok bersalin. Sebagian besar tenaga kesehatan tahu bahwa profilasksi vitamin $\mathrm{K}$ tidak memberikan efek samping berbahaya terhadap bayi sehingga mereka memberikan profilasksi vitamin $\mathrm{K}$ pada bayi baru lahir dan selalu menyediakan vitamin $\mathrm{K}$ di puskesmas/pondok bersalin.

Pelatihan untuk mengembangkan pengetahuan dan pengenalan resiko perdarahan pada bayi baru lahir penting 
diberikan pada setiap tenaga penolong persalinan seperti bidan agar bisa mengenal dan melakukan pencegahan vitamin $\mathrm{K}$ sesuai protokol yang telah ditentukan. Perlu penerapan protokol yang jelas bagi petugas kesehatan agar dapat memberikan suntikan vitamin $\mathrm{K}$ tanpa harus menunggu persetujuan dari dokter.

\section{SIMPULAN}

Dari hasil penelitian dapat disimpulkan bahwa:

1. Sebagian besar tenaga penolong persalinan mempunyai tingkat pengetahuan tergolong baik, berpendapat bahwa profilaksis vitamin $\mathrm{K}$ harus diberikan pada semua bayi baru lahir, berpendapat bahwa profilakisis vitamin $\mathrm{K}$ bermanfaat untuk mencegah perdarahan bayi baru lahir, dan setuju vitamin $\mathrm{K}$ harus selalu tersedia di puskesmas/pondok bersalin.

2. Sebagian tenaga penolong persalinan berpendapat bahwa tidak ada efek samping yang berbahaya dari profilaksis vitamin $\mathrm{K}$.

3. Hampir semua tenaga penolong persalinan memberikan profilaksis vitamin $\mathrm{K}$ dan menyediakan vitamin $\mathrm{K}$ di puskesmas/pondok bersalin.

\section{DAFTAR PUSTAKA}

1. Emilia O, Freitag H. Tetap Bugar dan Energik Selama Hamil. Jakarta: Agro Media, 2010; p. 163.

2. Mulyono E. Pemberian injeksi vitamin $K_{1}$ profilaksis pada bayi baru lahir. [cited 2011 Dec 8]. Available from: http://www.gizikia.depkes.go.id/wpcontent/uploads/downloads/2011/09/PE DOMAN-TEKNIS-VIT-K1.pdf.

3. Moeslichan MZ, Surjono A, Khosin S, Gatot HD, Indarso F. Pemberian profilaksis vitamin $\mathrm{K}$ pada bayi baru lahir. HTA Indonesia, 2003.

4. Wahyudi W. Epidemiologi penyakit PDVK. [cited 2011 Dec 8]. Available from: http://buk.depkes.go.id/index.php?optio $\mathrm{n}=\mathrm{com} \_$docman\&task.

5. Peter M, Hasselt PM, de Koning TJ, Kvist $\mathbf{N}$, de Vries E, Lundin CR. Prevention of vitamin $\mathrm{K}$ deficiency bleeding in breastfed infants: lessons from the Dutch and Danish biliary atresia registries. Pediatrics. 2008;121:857-3.

6. Tapan E. Pemberian profilaksis vitamin $\mathrm{K}$ pad abayi baru lahir. [cited 2011 Dec 8]. Available from: http://www.mailarchive.com/dokter@itb.ac.id/msg1109 1.html.

7. Lippi G, Franchini M. Vitamin $K$ in neonates: facts and myths. University Hospital of Parma, 2010; p. 4-8.

8. Boujan MK, Sharef KH. Change in hospital protocol regarding the use of vitamin $\mathrm{K}$ prophylaxis in newborn following a case of spontaneous subdural haematoma in a previously healthy 40-day-old infant. EMJH. 2013;19:502-4.

9. Tulchinsky TH. Vitamin K prophylaxis for newborns: a position paper. Hebrew University-Hadassah, 2007. 